\title{
PENERAPAN STUDENT WORKSHEETS PADA DISCOVERY LEARNING SEBAGAI GUIDANCE MAHASISWA DALAM MENEMUKAN KONSEP DAN USAHA PENINGKATAN PEMAHAMAN KOGNITIF
}

\author{
Ifa Muhimmatin \\ Iis Ni'matul Jannah \\ 1,2 \\ Universitas 17 Agustus 1945 Banyuwangi \\ E-mail: ifa.muhimmatin@untag-banyuwangi.ac.id, iis_jnh@yahoo.co.id
}

\begin{abstract}
Discovery learning is one of the approaches that applied to science learning. Discovery learning designed to engage students in an activity that leads them to "discover" the intended content. However, based on the results of the implementation of discovery learning previously, a crucial fact came up. Without guidance, students sometimes make discoveries other than as intended. This classroom action research conducted in four cycles. Each cycle consists of planning, implementation with observation, and reflection. The worksheets were applied in discovery learning as guidance for students in carrying out discovery activities. The subjects of the research were 15 students participating in plant morphology course. Data collected include students ability to find concepts; and students cognitive skills. Data analyzed with qualitative descriptive techniques.

The assessment of students' ability to find concepts increased in each cycle, from 2.87 in cycle 1, becomes 3.33 in the last cycle. This result shows that students are able to find the intended concept, according to the guidance given by the student worksheets. Assessment of students' cognitive skills shows the increase from the pretest score to the posttest score. In the first cycle, the increase in students' cognitive skills are 4.00; then 3.9 in cycle two; 4.97 in the third cycle; and 5.13 in the last cycle. Based on that data, can be concluded that the implementation of student worksheets on guided discovery learning can improve students' discovery ability and cognitive skills in plant morphology course.
\end{abstract}

Keywords: cognitive, discovery learning, guidance, worksheets

\begin{abstract}
Pembelajaran berbasis
penemuan (discovery learning) merupakan salah satu pendekatan pembelajaran yang sering diterapkan dalam pembelajaran sains. Discovery learning tampak menjadi model pembelajaran yang menjanjikan untuk beberapa alasan, salah satu alasan tersebut ialah mampu membuat peserta didik turut berperan aktif dalam proses pembelajaran. Keaktifan peserta didik dalam pembelajaran ini
\end{abstract}

tentu akan menghasilkan struktur dasar pengetahuan yang lebih baik pada jika dibandingkan dengan pembelajaran tradisional (Joolingen, 1999).

$$
\text { Istilah discovery dapat }
$$
diartikan dalam banyak makna, namun dalam pembelajaran sains istilah tersebut lebih diartikan sebagai langkah ilmuwan menemukan konsep baru; atau sebuah metode mengajar yang menuntun siswa memecahkan 
masalah dengan memahami konsep (Lucas, 1971). Discovery learning menurut Veermans (2003) mempunyai lima tahapan, yakni: tahap orientation, tahap hypothesis generation, hypothesis testing, conclusion, dan tahap regulation.

Discovery learning didesain untuk melibatkan mahasiswa dalam suatu kegiatan yang menuntun mereka untuk menemukan konsep tertentu. Namun kekhawatiran kadang masih ada, misalnya ketika mahasiswa menemukan konsep selain yang telah ditentukan oleh guru (Hammer, 1997: 485).

Hasil evaluasi terhadap penerapan discovery learning yang telah dilakukan pada mata kuliah morfologi tumbuhan di program studi pendidikan biologi Unniversitas 17 Agustus 1945 Banyuwangi tahun ajaran 2017-2018 menemukan adanya beberapa mahasiswa yang kurang memahami apa yang seharusnya dia temukan, sehingga akhirnya konsep yang dia temukan kurang sesuai dengan harapan tujuan pembelajaran. Hal ini diakibatkan antara lain karena kurangnya guidance yang diberikan oleh dosen selama kegiatan discovery learning berlangsung.

Penerapan discovery learning secara murni memang kurang memberikan umpan balik kepada mahasiswa sehingga memunculkan ambiguitas dalam menemukan konsep (Clark dkk. 2012). Mahasiswa seharusnya dibimbing agar dapat menemukan sendiri fenomena yang sedang dipelajari, kemudian data hasil penemuan tersebut harus didiskusikan oleh mahasiswa, dan ada alokasi waktu yang memadai untuk mengkomunikasikan hasil penemuan tersebut (Bodner dan Hunter, 1998). Hal tersebut menegaskan bahwa proses pembimbingan (guidance) dalam discovery learning sangatlah penting.

Sebuah penelitian meta analisis yang dilakukan oleh Alfieri, dkk. (2011) dengan sampel sebanyak 164 studi menunjukkan sebuah kesimpulan bahwa kegiatan discovery learning tanpa guidance tidak akan menguntungkan bagi mahasiswa. Kesimpulan dari sebuah kajian oleh Honomichl \& Chen (2012) juga menyatakan hal serupa. yakni bahwa guidance harusnya dimasukkan secara strategis ke dalam discovery learning. Hal ini karena guidance berperan penting dalam menuntun mahasiswa melakukan kegiatan penemuan.

Proses guidance pada discovery learning dapat berupa instruksi lisan misalnya pertanyaan, berupa demonstrasi, atau berupa media lain (Yulianti dan Saragih, 2015). Guidance yang disampaikan secara lisan mempunyai kelemahan, yakni guru kadang kurang runtut dalam menyampaikan tahapan kegiatan, sehingga siswa kurang dapat mengikuti guidance yang diberikan. Guidance seharusnya telah dipersiapkan oleh guru sejak sebelum proses pembelajaran dimulai. Salah satu guidance dalam bentuk media cetak yang dapat dipersiapkan sebelum pembelajaran ialah berupa 
lembar kerja mahasiswa (student worksheets).

Worksheet adalah bahan ajar cetak berupa lembar-lembar kertas yang berisi materi, ringkasan, dan petunjuk-petunjuk pelaksanaan tugas pembelajaran yang harus dikerjakan, yang mengacu pada kompetensi dasar yang harus dicapai (Prastowo, 2011). Student worksheets dapat diterapkan untuk mendukung tahapan discovery learning yang membutuhkan guidance, misalnya tahapan ketiga hingga kelima dari pembelajaran discovery learning, yakni tahapan hypothesis testing, conclusion, dan regulation. Worksheet yang sesuai dengan alur penerapan guided discovery learning akan mampu mengarahkan mahasiswa dalam kegiatan pembelajaran berbasis penemuan tersebut.

\section{METODE}

Penelitian ini merupakan Penelitian Tindakan Kelas (PTK) yang dilaksanakan dalam empat siklus. Setiap siklus terdiri dari tahap perencanaan, tahap pelaksanaan tindakan serta pengamatan, dan tahap refleksi (Sugiyono, 2013). Skema tahapan tiap siklus dapat dilihat pada Gambar 1. Siklus pertama membahas tentang folium (daun), siklus kedua tentang flos (bunga), siklus ketiga tentang inflorescentia (bunga majemuk), dan siklus keempat membahas tentang fructus (buah). Setiap siklus dilaksanakan dalam dua kali perkuliahan yang setara dengan 2 x 90 menit.

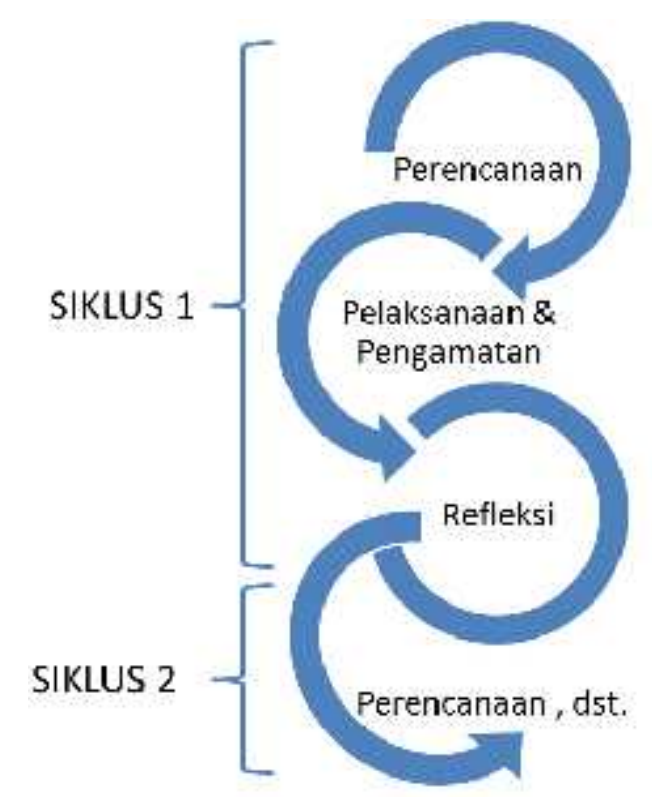

Gambar 1. Skema Siklus PTK

Pelaksanaan tindakan kelas yaitu dengan menerapkan model pembelajaran guided discovery learning yang terdiri dari lima tahap: 1). tahap orientation; 2). tahap hypothesis generation; 3). tahap hypothesis testing; 4). tahap conclusion; dan 5). tahap regulation. Student worksheets diterapkan pada tahap ketiga hingga kelima dari tahapan diatas. Penerapan Student worksheets ini ialah sebagai guidance yang dapat membantu mahasiswa dalam melaksanakan kegiatan penemuan.

Student worksheets dikemas dalam bentuk buku berukuran A4. Kerangka isi student worksheets terdiri dari:

- Sampul

- Kata pengantar

- Petunjuk penggunaan

- Daftar isi

- Delapan (8) bab tentang morfologi tumbuhan. Tiap bab berisi: 
- "Judul bab" beserta nomor urut bab

- "Uraian singkat" disertai gambar untuk mengarahkan mahasiswa ke topik yang akan dipelajari

- “Kegiatan penemuan” yang dapat menuntun mahasiswa melakukan

kegiatan discovery learning dengan memanfaatkan tumbuhantumbuhan yang ada di lingkungan sekitar

- "Materi pokok" untuk membantu mahasiswa mengkaji kembali hal-hal yang telah ditemukan dalam kegiatan penemuan dan membandingkannya dengan teori / pustaka

- "Lembar diskusi" untuk menuntun mahasiswa berpikir kembali tentang prediksi awal dibanding dengan hasil penemuan, dan membimbing mahasiswa

mempresentasikan hasil penemuannya.

Subyek penelitian terdiri dari 15 mahasiswa semester tiga yang sedang menempuh mata kuliah morfologi tumbuhan. Data penelitian yang dihimpun meliputi: 1). nilai kemampuan menemukan konsep yang diperoleh melalui observasi; dan 2). data hasil belajar kognitif yang diperoleh melalui pretest serta postest pada setiap siklus. Kemampuan menemukan konsep mahasiswa dinilai berdasarkan: kinerja dalam proses menemukan pada tahap hypothesis testing; dan kualitas hasil penemuan yang dikemukakan mahasiswa di tahap conclusion. Kedua data yang diperoleh dianalisis menggunakan teknik analisis deskriptif kualitatif.

\section{HASIL DAN PEMBAHASAN}

Tahap persiapan dilakukan dengan menyiapkan rencana kegiatan pembela-jaran dan alat penilaian yang sesuai dengan langkah discovery learning, menyiapkan student worksheets, serta menyusun lembar keterlaksanaan pembelajaran. Pada tahap pelaksanaan, dilakukan pembelajaran berbasis guided discovery learning berbantuan student worksheets yang didahului dengan pretest dan diakhiri dengan posttest pada tiap siklusnya. Kegiatan pembelajaran ini diikuti dengan observasi keterlaksanaan pembelajaran dan penilaian terhadap mahasiswa. Hasil dari tahap pelaksanaan kemudian dianalisis dan hasilnya menjadi bahan evaluasi untuk merencanakan kegiatan pembelajaran di siklus berikutnya.

Penelitian dilaksanakan dalam empat siklus pada mata kuliah morfologi tumbuhan yang membahas tentang morfologi daun, morfologi bunga, bunga majemuk, dan morfologi buah. Empat siklus penelitian tindakan ini dilaksanakan agar data yang didapatkan tentang kualitas discovery learning dan peningkatan hasil belajar dapat terlihat lebih jelas, serta meminimalisir munculnya faktor 
diluar variabel penelitian yang ikut berpengaruh.

Pelaksanaan pembelajaran ditiap siklusnya terdiri dari tahap orientation, tahap hypothesis generation, tahap hypothesis testing, tahap conclusion, dan tahap regulation. Pelaksanaan tahap orientation dan tahap hypothesis generation dipimpin oleh dosen dengan cara mengajukan beberapa pertanyaan penuntun. Pertanyaan penuntun ini merupakan bagian dari guidance. Tahap hypothesis testing dan tahap conclusion dilaksanakan oleh mahasiswa dengan berpegang pada student worksheets. Lalu tahap regulation kembali dipimpin oleh dosen sebagai upaya untuk memantapkan pemahaman mahasiswa. Hasil evaluasi terhadap keterlaksanaan pembelajaran ditiap siklus tersaji pada Tabel 1.

Tabel 1. Keterlaksanaan

Pembelajaran

\begin{tabular}{c|c|c}
\hline \multirow{2}{*}{ Siklus } & \multicolumn{2}{|c}{ Keterlaksanaan Pembelajaran } \\
\cline { 2 - 3 } & terlaksana & tidak \\
\hline 1 & $93,33 \%$ & $6,67 \%$ \\
\hline 2 & $100 \%$ & $0 \%$ \\
\hline 3 & $100 \%$ & $0 \%$ \\
\hline 4 & $100 \%$ & $0 \%$ \\
\hline Rerata & $98,25 \%$ & $1,67 \%$ \\
\hline
\end{tabular}

Pada keseluruhan siklus, keterlaksanaan pembelajaran mencapai persentase $98,25 \%$. Ketidakterlaksanaan pembelajaran secara sempurna terjadi pada siklus 1 , diakibatkan adanya keterbatasan waktu sehingga terdapat satu subbab yang harus dilewati. Namun hal ini tidak sampai mengganggu tahapan penerapan guided discovery learning.

Keberhasilan mahasiswa dalam menemukan konsep dilihat berdasar hasil penilaian terhadap kinerja menemukan, dan berdasar kualitas hasil penemuan mahasiswa. Tabel 2 merupakan hasil penilaian terhadap kinerja penemuan dan penilaian terhadap kualitas hasil penemuan di tiap siklus.

Komponen penilaian dari kinerja menemukan terdiri dari: ketrampilan mengamati, mengukur, mengklasifikasi, dan memprediksi yang dinayatakan dalam skala 0 (kategori 'tidak bekerja') hingga skala maksimal 4 (kategori 'sangat baik'). Berdasar data kinerja menemukan pada Tabel 2, rerata kinerja mahasiswa di siklus 1 ialah 2,73 dengan kategori 'cukup baik'. Pada siklus berikutnya terjadi peningkatan kinerja mahasiswa, hingga pada siklus terakhir tercatat rerata sebesar 3,4 atau dengan kategori 'baik'.

Tabel 2. Penilaian Kinerja dan Kualitas Hasil Penemuan

\begin{tabular}{c|c|c|c|c}
\hline \multirow{2}{*}{$\begin{array}{c}\text { Subyek } \\
\text { Penilaian }\end{array}$} & 1 & 2 & 3 & 4 \\
\cline { 2 - 5 } & \multicolumn{4}{|c}{ Siklus ke } \\
\hline $\begin{array}{c}\text { Kinerja } \\
\text { Penemuan }\end{array}$ & 2,73 & 2,87 & 3,13 & 3,40 \\
\hline $\begin{array}{c}\text { Hasil } \\
\text { Penemuan }\end{array}$ & 3,00 & 3,27 & 3,33 & 3,27 \\
\hline $\begin{array}{c}\text { Rerata } \\
\text { Kemampu } \\
\text { an'Mene- } \\
\text { mukan' }\end{array}$ & 2,67 & 3,07 & 3,23 & 3,33 \\
\hline Kualitas & $\begin{array}{c}\text { Cukup } \\
\text { baik }\end{array}$ & Baik & Baik & Baik \\
\hline
\end{tabular}

Peningkatan kinerja menemukan ini menunjukkan bahwa 
mahasiswa mulai terlatih untuk menemukan konsep dengan cara mengikuti tiap instruksi yang terdapat pada student worksheets. Kinerja mahasiswa dalam menemukan konsep terus meningkat ditiap siklus karena adanya dorongan dalam diri mereka untuk mempresentasikan hasil penemuan berupa konsep yang tepat dengan baik.

Hal ini sesuai dengan salah satu temuan yang dihasilkan dari penelitian Mahmoud (2014) pada siswa tingkat menengah. Hasil temuan tersebut menyatakan bahwa discovery learning membantu menghasilkan aktivitas dimana siswa belajar untuk diri mereka sendiri dan menerapkan pengetahuannya pada situasi baru. Hal inilah yang akhirnya menuntun siswa pada sebuah pembelajaran berbasis penemuan yang efektif.

Tabel 2 juga menunjukkan adanya rerata nilai kualitas hasil penemuan konsep oleh mahasiswa. Kemampuan menemukan konsep ini dinilai berdasar kesesuaian antara konsep yang dikemukakan mahasiswa pada presentasi hasil, dengan konsep pokok yang seharusnya ditemukan untuk menjawab hipotesis yang telah diajukan.

Secara umum rerata penilaian terhadap hasil penemuan mahasiswa menunjukkan hasil yang baik, dengan nilai 3,00 di siklus pertama dan nilai 3,27 pada siklus terakhir. Meskipun tidak mengalami peningkatan yang mencolok pada tiap siklusnya, namun rerata kemampuan menemukan konsep mereka telah masuk dalam kategori 'baik'. Artinya, konsep yang ditemukan mahasiswa telah sesuai dengan konsep pokok yang seharusnya ditemukan, dan konsep tersebut mampu menjawab pertanyaan-pertanyaan yang muncul pada tahap sebelumnya, yaitu tahap hypothesis generation.

Berdasar hasil penilaian kinerja dengan penilaian kualitas hasil penemuan, didapatkan rerata kemampuan mahasiswa dalam menemukan konsep. Rerata nilai kemampuan mahasiswa dalam menemukan konsep dapat dibuat diagram seperti pada Gambar 2.

Diagram Gambar menunjukkan bahwa pada tiap siklus terjadi peningkatan kemampuan mahasiswa dalam menemukan konsep. Pada siklus satu, rerata keberhasilan mahasiswa menemukan konsep ialah sebesar 2,87. Sedang pada siklus terakhir, rerata kemampuan menemukan konsep ialah sebesar 3,33. Peningkatan ini menunjukkan bahwa mahasiswa mampu menemukan konsep yang tepat, sesuai dengan guidance yang telah diberikan baik oleh dosen maupun oleh instruksi pada student worksheets. Hal ini sesuai dengan pendapat Kirschner \& Clark (2006) bahwa student worksheet dapat membimbing pebelajar secara sistematis untuk menemukan pengetahuan dan kompetensi yang diinginkan oleh guru. 


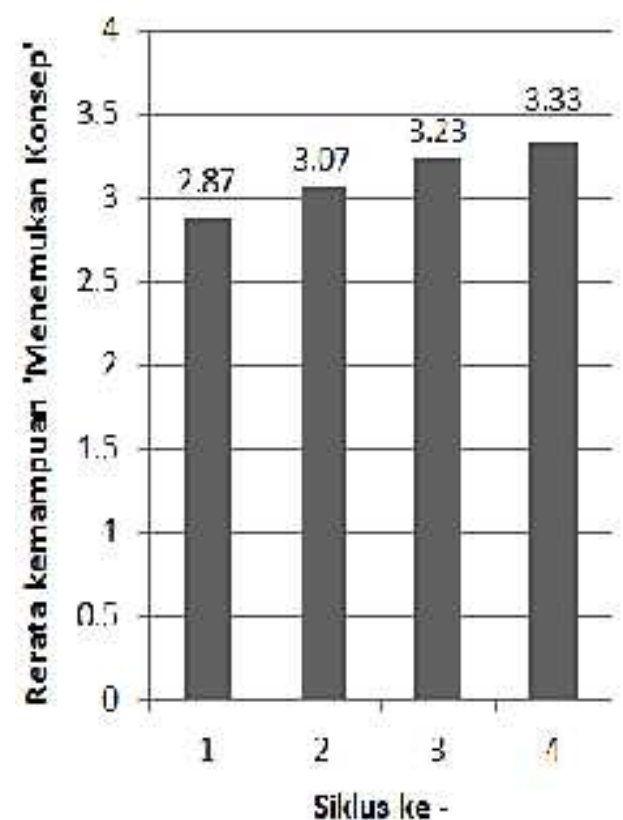

Gambar 2. Rerata Kemampuan Mahasiswa dalam Menemukan Konsep

Penilaian selanjutnya ialah penilai-an terhadap hasil belajar kognitif mahasiswa. Penilaian ini dilaksanakan melalui tes tulis yang dilakukan pada setiap awal siklus (pretest) dan pada tiap akhir siklus (posttest). Jenis soal tes ialah tes uraian terbuka dan berjumlah tiga hingga lima butir per test. Butir tes telah dianalisis validitas menggunakan rumus Pearson dan dinyatakan valid. Hasil tes kemudian dinilai menggunakan skala 0 sampai skala 10. Rangkuman hasil tes kognitif mahasiswa dapat dilihat pada Tabel 3.

Tabel 3. Hasil Tes Kognitif

\begin{tabular}{c|c|c|c|c|c}
\hline \multirow{2}{*}{$\begin{array}{c}\text { Jenis } \\
\text { Penilai- } \\
\text { an }\end{array}$} & \multicolumn{4}{|c|}{ Siklus ke - } & \multirow{2}{*}{$\begin{array}{c}\text { Re- } \\
\text { rata }\end{array}$} \\
\cline { 2 - 6 } & 1 & 2 & 3 & 4 & \\
\hline Pretest & 2,37 & 2,97 & 2,03 & 2,53 & 2,48 \\
\hline Postest & 6,37 & 6,87 & 7,00 & 7,67 & 6,98 \\
\hline Selisih & 4,00 & 3,90 & 4,97 & 5,13 & 4,50 \\
\hline
\end{tabular}

Hasil pretest menunjukkan bahwa kemampuan kognitif mahasiswa sebelum pembelajaran mempunyai rerata sekitar 2,48 pada skala 10. Sedangkan setelah proses pembelajaran, kemampun kognitif mahasiswa mempunyai rerata sebesar 6,98 pada skala 10. Hal ini menunjukkan bahwa proses pembelajaran berbasis guided discovery menyebabkan peningkatan kemamapuan kognitif mahasiswa.

Pada siklus pertama, terdapat kenaikan kemampuan kognitif mahasiswa sebesar 4,00; pada siklus dua terdapat kenaikan sebesar 3,9; pada siklus ketiga terdapat kenaikan sebesar 4,97; dan pada siklus terakhir, kenaikan kemampuan kognitif mahasiswa ialah sebesar 5,13. Kenaikan atau selisih nilai pretest dan postest ini tentu saja tidak dapat dibandingkan antar siklus karna tiap siklus mempunyai tingkat kesulitan materi ajar yang berbeda. Namun dari selisih antara nilai pretest dengan nilai posttest tersebut terlihat bahwa selalu terjadi peningkatan kemampuan kognitif mahasiswa setelah mengikuti kegiatan discovery learning.

Sebuah penelitian kuasi eksperimen dilaksanakan pada pembelajaran sains di sekolah menengah pertama oleh Martaida, dkk. (2017) dengan membandingkan antara pembelajaran discovery learning dengan pembelajaran tradisional. Hasil penelitian menyebutkan bahwa kemampu-an kognitif siswa yang dibelajarkan 
menggunakan discovery learning mem-punyai hasil yang lebih baik dibanding kemampuan kognitif siswa yang dibelajarkan menggunakan pembelajaran konvensional. Kembali pada hasil penelitian ini pada Tabel 3, akhirnya dapat dikatakan bahwa adanya peningkatan rerata kemampuan kognitif yang diperoleh mahasiswa merupakan hasil dari adanya kesempatan untuk 'menemukan' sendiri konsep materi ajar yang sedang dipelajari. Lalu andil dari student worksheets pada discovery learning adalah sebagai pemandu agar proses penemuan yang dilakukan mahasiswa dapat berjalan dengan lancar dan sesuai dengan tujuan pembelajaran.

\section{KESIMPULAN}

\section{Penilaian}

kemampuan menemukan konsep mahasiswa menunjukkan adanya peningkatan di tiap siklusnya. Pada siklus pertama, rerata keberhasilan mahasiswa menemukan konsep ialah sebesar 2,87; sedangkan pada siklus terakhir, rerata kemampuan menemukan konsep menjadi sebesar 3,33. Peningkatan ini menunjukkan bahwa mahasiswa mampu menemukan konsep yang tepat, sesuai dengan guidance yang telah diberikan baik oleh dosen maupun oleh student worksheets.

belajar kenilaian terhadap hasil memperlihatkan adanya selisih antara nilai pretest dengan nilai posttest. Selisih antara nilai pretest dengan nilai posttest ini menunjukkan terjadinya peningkatan kemampuan kognitif mahasiswa setelah mengikuti kegiatan discovery learning. Pada siklus pertama, terdapat kenaikan kemampuan kognitif mahasiswa sebesar 4,00; pada siklus dua terdapat kenaikan sebesar 3,9; pada siklus ketiga terdapat kenaikan sebesar 4,97; dan pada siklus terakhir, kenaikan kemampuan kognitif mahasiswa ialah sebesar 5,13.

Berdasar dua parameter tersebut dapat disimpulkan bahwa student worksheets dapat dijadikan guidance, dan penerapan student worksheets pada guided discovery learning dapat meningkatkan kemampuan menemukan dan hasil belajar mahasiswa di mata kuliah morfologi tumbuhan.

\section{SARAN}

(SW) pada pembelajaran berbasis penemuan terbimbing (guided discovery learning) dapat dilakukan pada pembelajaran sains lainnya. Namun sebelum penerapan SW, diperlukan adanya analisis terhadap kemampuan mahasiswa dalam memahami instruksi tertulis. Hal ini karena kemampuan mahasiswa dalam memahami instruksi tertulis berbedabeda, dan instruksi dalam student worksheets harus disesuaikan dengan kemampuan mayoritas mahasiswanya.

\section{UCAPAN TERIMA KASIH}

Terima kasih kepada Direktorat Riset dan Pengabdian Masyarakat (DRPM) Kementerian Riset 
Teknologi dan Pendidikan Tinggi atas dukungan dana tahun anggaran 2018 untuk menunjang pelaksanaan penelitian ini.

\section{DAFTAR RUJUKAN}

Alfieri, L. Brooks, P. J. Aldrich, N. J. Tenenbaum. 2011. Does Discovery-Based Instruction Enhance Learning?. Journal of Educational Psychology, Vol. 103 (1): 1-18.

Bodner, G.M. \& Hunter W. J. F. 1998. What Happens When Discovery Laboratories Are Integrated into the Curriculum at a Large Research University? Journal of Springer Verlac, Vol. 3 (3): 3249.

Clark, R.E., Kirchner, P.A., John Sweller. 2012. Putting student to the path of learning. Journal American Educator, Vol. 4 (1): 6-11.

Hammer, D. 1997. Cognition and Instruction: Discovery Learning and Discovery Teaching. USA: Lawrence Erlbaum Associates, Inc.

Honomichl, R. D \& Chen, Z. 2012. The Role of Guidance in Children's Discovery Learning. WIREs Cognitive Science, Vol. 3: 615-622.

Joolingen, W. V. 1999. Cognitive tools for discovery learning. International Journal of Artificial Intelligence in Education, Vol. 10 : 385-397.

Kirschner, P. A., \& R.E. Clark. 2006. Why Minimal Guidance During
Instruction Does Not Work: An Analysis of the Failure of Constructivist, Discovery, Problem-Based, xperiential, and Inquiry-Based Teaching. Journal Educational Psychologist, Vol. 41 (2): 7586.

Lucas, A.M. 1971. Creativity, Discovery, and Inquiry in Science Education. The Australian Journal of Education, Vol. 5 (2): 185-196. Mahmoud, A. K. A. 2014. The Effect of Using Discovery Learning Strategy in Teaching Grammatical Rules to first year General Secondary Student on Developing Their Achievement and Metacognitive Skills. International Journal of Innovation and Scientific Research, Vol. 5 (2): 146-153.

Martaida, T. Bukit, N. Ginting, E.M. 2017. The Effect of Discovery Learning Model on Student's Critical Thinking and Cognitive Ability in Junior High School. IOSR Journal of Research \& Method in Education. Vol.7 (Issue 6 Ver. I): 01-08.

Prastowo, A. 2011. Panduan Kreatif Membuat Bahan Ajar Inovatif. Yogyakarta: Diva Press.

Sugiyono, P. D. 2013. Metode Penelitian Pendidikan: Pendekatan Kuantitatif, Kualitatif, dan $R \quad \& \quad D$. Bandung: Alfabeta.

Veermans, K. 2003. Intelligent support for discovery learning. 
Netherlands: Twente University Press.

Yulianti, K. \& Saragih. 2015. The Development of Learning Devices Based Guided Discovery Model to Improve Understanding Concept and Critical Thinking Mathematically Ability of Students at Medan Islamic Junior High School. Journal of Education and Practice, Vol. 6 (24): 116-128. 